\title{
К ВОПРОСУ ЭКОНОМИЧЕСКОГО СТИМУЛИРОВАНИЯ ПОДРАЗДЕЛЕНИЙ ВЫСШЕГО УЧЕБНОГО ЗАВЕДЕНИЯ
}

\author{
(c) 2018 Григорьева Ирина Васильевна \\ кандидат филологических наук, доцент, кафедра иностранных языков № 3 \\ Российский экономический университет им. Г.В. Плеханова \\ 115093, г. Москва, Стремянный пер., 36 \\ E-mail: i911g@mail.ru \\ (c) 2018 Долгова Елена Геннадьевна \\ кандидат филологических наук, доцент, кафедра иностранных языков № 3 \\ Российский экономический университет им. Г.В. Плеханова \\ 115093, г. Москва, Стремянный пер., 36 \\ E-mail: artzishevich@inbox.ru \\ (c) 2018 Федорова Анна Валерьевна \\ кандидат филологических наук, доцент, кафедра иностранных языков № 3 \\ Российский экономический университет им. Г.В. Плеханова \\ 115093, г. Москва, Стремянный пер., 36 \\ E-mail:zhanna495@gmail.ru \\ (c) 2018 Быстрова Анастасия Владимировна \\ преподаватель кафедры иностранных языков № 3 \\ Российский экономический университет им. Г.В. Плеханова \\ 115093, г. Москва, Стремянный пер., 36 \\ E-mail: Eyer89@gmail.com
}

Актуальность стимулирования сотрудников высших учебных заведений в экономическом аспекте приобрела в Российской Федерации особую значимость в условиях мирового финансового кризиса. Объектом исследования являются совокупность подразделений высших учебных заведений, а предметом - вопросы экономического стимулированиях их сотрудников. Теоретическое и методологическое значение статьи заключается в развитии классификационной группировки подразделений высшего учебного заведения в аспекте воздействующих на их сотрудников стимулов экономического характера, а практическое - в выявлении и ранжировании проблем анализируемого процесса.

Ключевые слова: высшее учебное заведение, проблемы, эффективность, экономическое стимулирование, подразделение, лингвистика.

Эффективность функционирования высшего учебного заведения в целом и его подразделений в частности определяется множеством параметров, важнейшие из которых связаны с применяемыми методиками в сфере образования [5, с.23], технической базой и персоналом. Причем большинство авторитетных изданий [1, 2] указывает, что основным фактором успешного развития высшего учебного заведения в современных условиях является сбалансированное сотрудничество с его персоналом.

Основой эффективного взаимодействия с персоналом высшего учебного заведения является система материальных и нематериальных стимулов, формирующих мотивацию к труду как отдельно взятого сотрудника, так и весь коллектив в целом. Структура указанной системы не является универсальной и может различаться в зависимости от страны применения по относительному вкладу материальных и нематериальных составляющих. Примеры типовых структур стимулирования персонала высших учебных заведений в различных странах мира [4] в 2017 году приведены в табл. 1.

Данные табл. 1 позволяют сделать следующие выводы:

- за анализируемый период времени в шести рассмотренных странах существенное 
Таблица 1. Типовые структуры стимулирования персонала высших учебных заведений в различных странах мира в 2017 году [4], в\%

\begin{tabular}{|l|l|l|}
\hline \multicolumn{1}{|c|}{ Наименование страны } & $\begin{array}{c}\text { Доля материальных стимулов в } \\
\text { вознаграждении персонала ВУЗа }\end{array}$ & $\begin{array}{c}\text { Доля нематериальных стимулов в } \\
\text { вознаграждении персонала ВУЗа }\end{array}$ \\
\hline США & 72,62 & 27,38 \\
\hline Англия & 70,57 & 29,43 \\
\hline Германия & 68,42 & 31,58 \\
\hline Китай & 60,14 & 39,86 \\
\hline Япония & 56,21 & 43,79 \\
\hline Россия & 88,58 & 11,42 \\
\hline Среднее значение & 69,42 & 30,58 \\
\hline
\end{tabular}

превалирование в системе стимулирования персонала высших учебных заведений имели материальные стимулы, доля которых превосходила долю нематериальных стимулов в 2,27 раза;

- странами - лидерами в вопросах нематериального стимулирования персонала высших учебных заведений в 2017 году являлись Япония, Китай и Германия (доли нематериальных стимулов для них превышали среднюю отметку в $30 \%)$;

- явный акцент на материальное стимулирование имел место в таких развитых странах как США и Англия (доли материальных стимулов здесь составили 72,62\% и 70,57\% соответственно);

- сотрудники высших учебных заведений России стимулировались преимущественно (на 88,58\%) в материальной форме.

Было выяснено, что типовой перечень экономических стимулов персонала высшего учебного заведения в России включает следующе позиции, обозначенные в табл. 2.

Содержание табл. 2 свидетельствует о наличии следующего:
- наиболее значимыми экономическими стимулами в высших учебных заведениях России в 2017 году были: заработная плата (совокупная значимость на уровне 58,92\%) и совокупность надбавок и доплат (совокупная значимость на уровне 22,54\%);

- далее следовали разнообразные премии, уровень значимости которых не превышал $11,61 \%$;

- чуть менее 5\% приходилось на бонусы (совокупная значимость на уровне 4,52\%);

- на учредительные выплаты, занимающие предпоследнее место в анализируемом перечне позиций, приходилось чуть менее двух процентов от совокупных материальных выплат;

- уровень значимости прочих экономических стимулов не превышал одного процента.

Для определения уровня эффективности экономического стимулирования высших учебных заведений в России в 2017 году был проведен анализ удовлетворенности сотрудников в разрезе отдельных подразделений (табл. 3).

По табл. 3 поясним следующие моменты:

- уровень удовлетворенности сотрудников определяется отношением количества удовлет-

Таблица 2. Типовые позиции экономических стимулов персонала высшего учебного заведения в России (данные за 2017 год) [3], в\%

\begin{tabular}{|l|l|l|}
\hline \multicolumn{1}{|c|}{$\begin{array}{c}\text { Наименование } \\
\text { экономического стимула }\end{array}$} & \multicolumn{1}{|c|}{$\begin{array}{c}\text { Содержание } \\
\text { экономического стимула }\end{array}$} & $\begin{array}{c}\text { 3начимость эконо- } \\
\text { мического стимула }\end{array}$ \\
\hline Заработная плата & Основная и дополнительная & 58,92 \\
\hline Надбавки и доплаты & $\begin{array}{l}\text { Молодым специалистам, за наличие ученой степе- } \\
\text { ни, за наличие звания и прочие }\end{array}$ & 22,54 \\
\hline Премии & $\begin{array}{l}\text { Ежегодные, полугодовые, квартальные, месячные и } \\
\text { прочие }\end{array}$ & 11,61 \\
\hline Бонусы & $\begin{array}{l}\text { По итогам реализации проектов, грантов и прочих } \\
\text { мероприятий }\end{array}$ & 4,52 \\
\hline Учредительные выплаты & $\begin{array}{l}\text { По результатам работы учрежденных малых инно- } \\
\text { вационных предприятий }\end{array}$ & 1,74 \\
\hline Прочие экономические стимулы & $\begin{array}{l}\text { Выплаты в условной денежной форме (предоставле- } \\
\text { ние льгот на жилье, туристические путевки и т.д.) }\end{array}$ & 0,67 \\
\hline
\end{tabular}


Таблица 3. Данные по удовлетворенности сотрудников высших учебных заведений в России в 2017 году их экономическим стимулированием в разрезе отдельных подразделений, в\%

\begin{tabular}{|l|l|l|}
\hline $\begin{array}{c}\text { Подразделения высшего учебного } \\
\text { заведения (основные позиции) }\end{array}$ & $\begin{array}{c}\text { Уровень удовлетворенности } \\
\text { (усредненные значения), }\end{array}$ & $\begin{array}{c}\text { Уровень текучести кадров } \\
\text { (производная интеграция) }\end{array}$ \\
\hline Физико-математические & 69,38 & Низкий \\
\hline Химические & 81,58 & Низкий \\
\hline Инженерные & 59,58 & Средний \\
\hline Финансово-экономические & 71,36 & Низкий \\
\hline Образовательные & 80,93 & Высокий \\
\hline Правовые & 37,85 & Низкий \\
\hline Медийные & 91,58 & Средний \\
\hline Спортивные & 73,90 & Высокий \\
\hline Биологические & 90,55 & Низкий \\
\hline Медицинские & 55,19 & Низкий \\
\hline Информационно-технологические & 78,51 & Низкий \\
\hline Экологические & 59,89 & Высокий \\
\hline Геологические & 41,48 & Средний \\
\hline Психологические & 52,15 & Средний \\
\hline Международных отношений & 46,49 & Средний \\
\hline Лингистические & 83,82 & Высокий \\
\hline Прочие & 39,38 & Высокий \\
\hline
\end{tabular}

воренных сотрудников в рамках одного подразделения на общее количество сотрудников по подразделению;

- уровень удовлетворенности сотрудников подразделения высшего учебного заведения измеряется в процентах;

- минимальное значение уровня удовлетворенности сотрудников равно 0\% (характеризует отсутствие удовлетворенности у сотрудников подразделения высшего учебного заведения их экономическим стимулированием);

- максимальное значение исследуемого показателя равно 100\% (характеризует полную удовлетворенность сотрудников подразделения высшего учебного заведения их экономическим стимулированием).

На основе данных табл. 3 можно сделать вывод, что:

- наименее удовлетворенными в 2017 году в плане экономического стимулирования являлись такие подразделения высших учебных заведений в России, как: образовательные (уровень удовлетворенности сотрудников 37,85\% на фоне низкой текучести кадров); лингвистические (уровень удовлетворенности сотрудников 39,38\% на фоне высокой текучести кадров) и экологические (уровень удовлетворенности сотрудников 41,48\% на фоне средней текучести кадров);

- в более стабильном положении находились следующие подразделения высших учебных заведений: прочие (уровень удовлетворенности сотрудников 45,51\% на фоне средней текучести кадров); геологические (уровень удовлетворенности сотрудников 52,15\% на фоне средней текучести кадров); сферы услуг (уровень удовлетворенности сотрудников 59,58\% на фоне средней текучести кадров) и другие подразделения от $45 \%$ до $60 \%$;

- промежуточное положение за анализируемый период времени в плане удовлетворенности текущим экономическим стимулированием занимали: физико-математические (уровень удовлетворенности сотрудников 69,38\% на фоне низкой текучести кадров); инженерные (уровень удовлетворенности сотрудников 71,36\% на фоне низкой текучести кадров); медийные (уровень удовлетворенности сотрудников 73,90\% на фоне высокой текучести кадров) и другие подразделения высших учебных заведений в России и другие подразделения от 61\% до 80\%;

- наиболее удовлетворены системой экономического стимулирования в 2017 году были следующие подразделения высших учебных заведений: финансово-экономические (уровень удовлетворенности сотрудников 80,93\% при вы- 
сокой текучести кадров); химические (уровень удовлетворенности сотрудников 81,58\% при низкой текучести кадров); правовые (уровень удовлетворенности сотрудников 91,58\% при средней текучести кадров) и другие подразделения от $81 \%$ до $100 \%$.

В процессе изучения уровня удовлетворенности экономическим стимулированием сотрудников подразделений высших учебных заведений в России в 2017 годы были выявлены приведенные ниже проблемы:

- сравнительно низкий уровень заработной платы для высших учебных заведений в России относительно развитых стран (многие респонденты, в частности, сотрудники лингвистических подразделений, отмечали, что в 2017 году уровень их заработной платы составлял в пять раз ниже относительно ставок сотрудников на аналогичных должностях в такой стране, как США и более чем в шесть раз ниже, чем в Англии). Содержание данной проблемы в России зачастую усиливается плановыми сокращениями нагрузки профессорско-преподавательского состава;

- недостаточное развитие системы дифференциального стимулирования сотрудников отдельных подразделений в рамках высшего учебного заведения. Суть данной проблемы состоит в том, что для отдельных подразделений высшего учебного заведения (например, биологических и геологических) применение бонусных, учредительных выплат и прочих экономических стимулов в значительной степени затруднено, ввиду специфики их деятельности. Исходя из этого совокупный уровень их доходов в рамках существующей системы экономического стимулирования является низким, относительно других подразделений, более адаптированных к новым условиям работы (например, экономических и информационных);
- наличие организационной непропорциональности, приводящей к тому, что многие подразделения высших учебных заведений в России закрепляются (или входят в состав) за другими подразделениями, напрямую с ними не коррелирующими (например, лингвистическими и экономическими). При этом последние подразделения вступают как доминанты, а первые, как реципиенты). Это приводит к несбалансированному распределению ключевых показателей эффективности их работы, и, как следствие к значительной дифференциации в оплате труда за аналогичный объем работы.

Для разрешения обозначенных проблем в сфере экономического стимулирования подразделений высших учебных заведений в России может быть целесообразна реализация следующих мероприятий:

- рассмотреть на законодательном уровне вопрос повышения дополнительных надбавок к заработной плате остепененным сотрудникам высших учебных заведений безотносительно занимаемой ими должности в том или ином подразделении;

- модернизировать методическую базу распределения экономического стимулирования между различными подразделениями высшего учебного заведения;

- более обоснованно подойти к вопросу организационной корреляции разноплановых подразделений высшего учебного заведения.

Таким образом, можно сделать вывод, что процесс экономического стимулирования подразделений высшего учебного заведения в России в будущем может быть оптимизирован за счет решения обозначенного ряда проблем, а также, например, из за пересмотра опыта работы с расширенной системой материальных стимулов, активно применяемой в развитых зарубежных странах.

\section{Библиографический список}

1. Бабаков, А.В. Задачи инновационного развития и методы корпоративного стимулирования разработчиков / А.В. Бабаков // Экономические науки. 2016. № 4. С. 64-68.

2. Зельднер, А.Г. Стимулы привлечения трудовых ресурсов на территории опережающего социально-экономического развития // Вопросы экономики и права. 2017. № 8. С. 29-32.

3. Журнал «Управление компанией» [Электронный ресурс]: Аналитические материалы - Официальный сайт журнала «Управление компаний», 2018. - Режим доступа: https://www.zhuk.net

4. Компания Deloitte Touche Tohmatsu [Электронный ресурс]: Аналитические материалы - Официальный сайт компании Deloitte Touche Tohmatsu, 2018. - Режим доступа: https://www2.deloitte.com

5. Drago, Robert and Garvey, Gerald T. (1998). 'Incentives for helping on the job: theory and evidence,' Journal of Labor Economics, vol. 16, no. 1, pp. 1-25. 